\title{
Process modeling for historical buildings restoration: an innovation in the management of cultural heritage
}

\author{
Ada Malagnino ${ }^{1}$, Giovanna Mangialardi ${ }^{1}$, Giorgio Zavarise ${ }^{2}$, Angelo Corallo ${ }^{1}$ \\ ${ }^{1}$ Department of Engineering for Innovation, University of Salento, Campus University Ecotekne, Lecce, Italy \\ ${ }^{2}$ Department of Structural Engineering, Construction and Geotechnics, Polytechnic of Turin, Torino, Italy
}

\begin{abstract}
Cultural heritage is a complex ecosystem requiring innovative methods and techniques to facilitate its restoration, management and valorization. In detail, restoration processes have to preserve the original characteristics of historical buildings or sites, by involving different professional figures, each one with different roles, responsibilities and skills. In this light, a system that facilitates the information management, supported by new technologies, could allow more precise, efficient and traceable information exchange and could optimize the construction and management operative phase. Starting from these assumptions, the research proposes the application of a new integrated approach to a restoration process of a historical building. It consists of applying Business Process Management (BPM) approach and Building Information Modeling (BIM) methodology to provide valuable insights to optimize the data flow, to gather information and to share knowledge during the restoration process, by optimizing the whole lifecycle management process, by facilitating the ordinary and extraordinary maintenance. All these aspects are essential and strategic for the Italian cultural heritage.
\end{abstract}

\section{Section: RESEARCH PAPER}

Keywords: restoration; Historical Building Information Modeling; Business Process Modeling

Citation: Ada Malagnino, Giovanna Mangialardi, Giorgio Zavarise, Angelo Corallo, Process modeling for historical buildings restoration: an innovation in the management of cultural heritage, Acta IMEKO, vol. 7, no. 3, article 15, October 2018, identifier: IMEKO-ACTA-07 (2018)-03-15

Section Editor: Egidio De Benedetto, University of Salento, Italy

Received April 30, 2018; In final form September 21, 2018; Published October 2018

Copyright: (C) 2018 IMEKO. This is an open-access article distributed under the terms of the Creative Commons Attribution 3.0 License, which permits unrestricted use, distribution, and reproduction in any medium, provided the original author and source are credited

Funding: This work was supported by Italian Ministry of University and Research, through the PRIN 2015 funding scheme (project 2015JW9NJT - Advanced mechanical modeling of new materials and structures for the solution of 2020 Horizon challenges

Corresponding author: Ada Malagnino, ada.malagnino@unisalento.it

\section{INTRODUCTION}

Cultural heritage is a complex ecosystem requiring innovative methods and techniques to facilitate its management and valorisation. In particular, restoration processes are very complex, considering that the original characteristics of historical buildings or sites must be preserved and that different professional figures, having different roles, responsibilities and skills, are involved [1].

The correct management of the informative flows and knowledge, potentially accumulated for decades, becomes fundamental for the cultural heritage enhancement, since it is an expression of the ways of living, developed by a community and passed on from generation to generation, including customs, practices, places, objects, artistic expressions and values [2].
The restoration of historic buildings is particularly relevant in Italy, because it is a country characterized by a big cultural patrimony unique in the world.

A long and laborious legislative path has resulted in the laws issuance aimed at defining the concept of cultural heritage and its preservation. In Italy, for the cultural heritage, it is currently in force the Legislative Decree no. 42/2004 named "Codice dei Beni Culturali e del Paesaggio". The Decree regulates cultural and landscape heritage and also defines the "minor architectures" as monuments and environmental assets in close proximity of other monumental architectures, by referring to the building's importance, considered historical even if humble.

In addition, the Legislative Decree no. 310/1964, named "Costituzione di una commissione d'indagine per la tutela e la valorizzazione del patrimonio storico, archeologico, artistico e 
del paesaggio", identifies the historical town centres as a new class, defining them as "urban settlements that constitute cultural unity or the original and authentic settlements part".

The building cultural interest is not equivalent to the historical-artistic high value. For this reason, not all the historical buildings are bound by law [3].

The cultural heritage context is quite varied and complex. It involves, in fact, different actors and different procedural processes in relation to the kind of intervention and to the kind of historical building.

Another structural characteristic is that cultural and historical heritage is exposed to a continuing degradation risk. Degradation process may be aggravated and accelerated by environmental conditions or catastrophic events and by the lack of adequate forms of continuous monitoring and maintenance.

In Italy, these continuous care practices of cultural assets and the good practices diffusion among institutions have been neglected by owners and property managers, as the following pictures show (figure 1,2,3). The lack of maintenance operations not only implies the aesthetic degradation of materials and buildings, but also the structural and functional characteristics loss. Therefore, when a catastrophic event occurs, such as an earthquake, the probability of the structural and non-structural elements collapse is much higher.

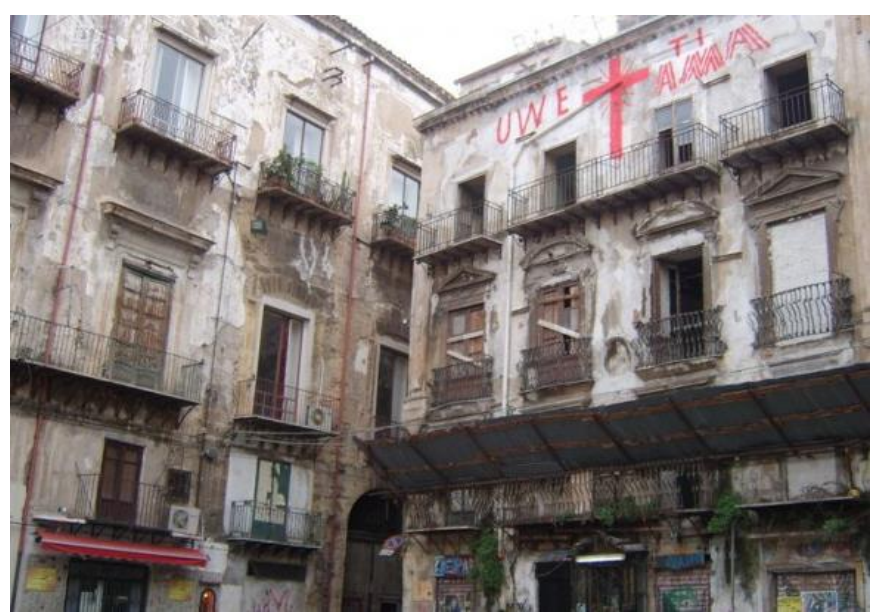

Figure 1. Historical buildings in Piazza Garaffello, Palermo (PA), Italy. (Source: https://commons.wikimedia.org/wiki/File:Piazza_Garraffello__panoramio.jpg)

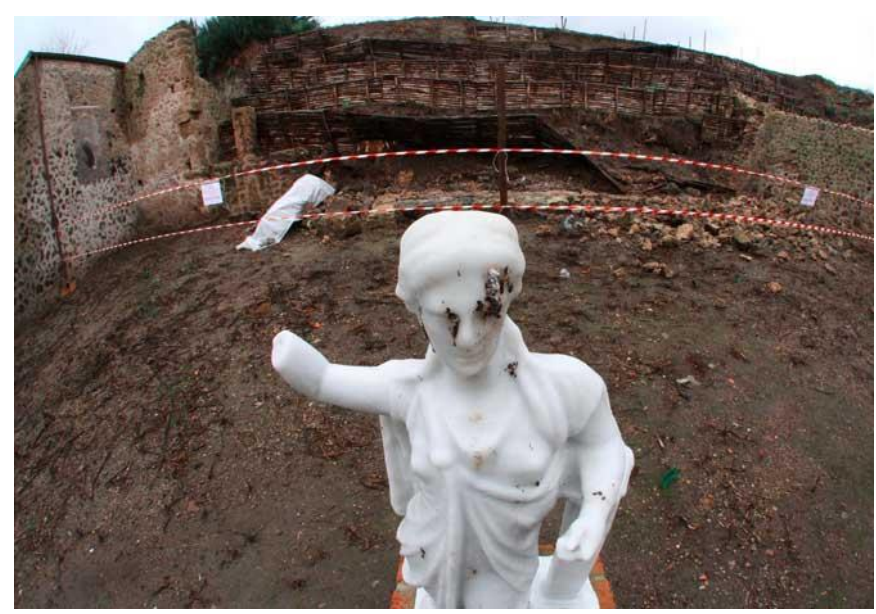

Figure 2. Pompei Archeological site (NA), Italy.

(Source: https://culture.globalist.it/arti/2017/10/12/come-cambiano-isaperi-e-la-cultura-grazie-alla-rete-2013000.html)

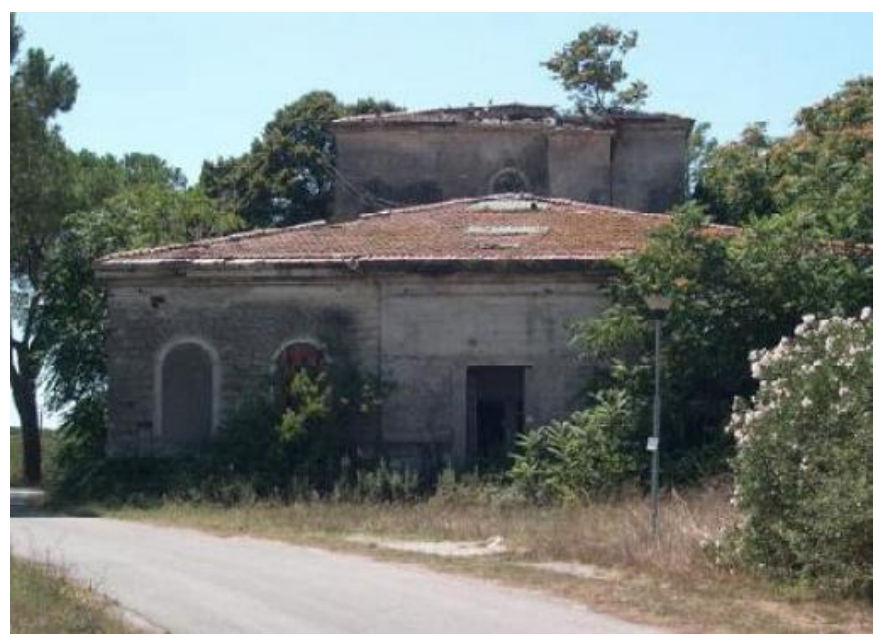

Figure 3. Guglielmo Marconi's telegraphic radio station, Coltano (PI), Italy. (Source: http://www.5avi.net/2018/01/18/la-palazzina-marconi-coltanoriflessione-sulla-tutela/)

The adoption of maintenance and conservation dynamic plans (like a building dossier) can give a response to the sector development need. These plans would provide cognitive, conservative and economic benefits for a better management of cultural heritage, including preventive and predictive maintenance.

The new non-invasive technologies for surveys or the new methodologies of remote representation, more developed in other sectors, represent a potential to support such management. Examples are low-cost sensors from the Internet of Things, widespread in the automotive and aerospace sectors, and Digital Twins [4]. The need for new scenarios in the cultural heritage field is suggested by the awareness that maintenance should not be considered as a set of activities linked to a catastrophic event, but it should be considered as a set of complex and continuous activities that includes observation, evaluation, registration, programmed conservation and requires specialist skills during the building lifecycle.

As regards built heritage, historic buildings and monuments, the maintenance activities have always been considered as the prevailing mode of intervention on the existing city, starting from the restoration debate at the end of the nineteenth century, as well as various international Restoration Charters (Charter of Athens 1931, Italian Restoration Charter 1932, Charter of Venice 1964, etc.) [5].

The Legislative Decree no. 42/2004, mentioned above, is the main legislative reference of the sector and includes the following maintenance definition (Art. 29, paragraph 3): "complex of activities and interventions for the control of the cultural heritage and the maintenance of integrity, functional efficiency and the identity of the good and its parts". This definition underlines the idea that also maintenance is based on collection and management of information produced during the activities and the interventions.

Technological innovation, and especially process innovation (new management and prevention approaches), could allow to reduce, delay and, in particular, prevent degradation and, at the same time, reduce the maintenance and restoration costs. Process management could represent the first step to innovation in this field, generally slow to change, to redefine the govern modality for the cultural heritage.

In this light, a methodology that facilitates the information management, supported by new technologies in the Internet of 
Things and Industry 4.0 era, could allow more precise and traceable information exchange, by optimizing the building management.

This paradigm shift could represent the key for processes innovation of the cultural heritage, such as restoration, management and enhancement, by adopting theories and practices usually applied to other fields, such as Business Process Management (BPM) discipline, that manages processes to improve business performance outcomes and operation agility.

The data digitalization, whose proper utilization strongly depends on their analysis and interpretation, could optimize knowledge management and sharing among the multidisciplinary team, according to the Building Information Modeling (BIM) approach, which aims to manage the whole building lifecycle in a common data environment, based on a three-dimensional informative and parametric model.

A common data environment is a kind of online platform for collecting, managing and sharing (historical) building information through different people and process phases. For example, it facilitates the information exchange from the restoration phase to the management phase, where even the stakeholders involved are different.

In detail, BPM technique enables the processes modelling and the identification of roles and relationships among different stakeholders and among different types of documentation, while BIM methodology enables a collaborative common environment, where a 3D virtual model is the building data container.

Starting from these assumptions, this research proposes the application of a new integrated approach to a restoration process of a historical building. It consists in applying BPM approach and BIM methodology to provide valuable insights to optimize the data flow, gather information and share knowledge during the restoration process through lifecycle management.

The paper is divided into six Sections, including the introduction. Section 2 presents a brief review of the BIM, $\mathrm{BPM}, \mathrm{BPMN}$ theoretical background and a review of the application of these approaches on cultural heritage process management. Section 3 introduces the research settings and the methodology. Section 4 presents the application of BPM approach and BIM methodologies for the optimization of the restoration process. Section 5 discusses findings, and finally, Section 6 concludes the paper and identifies challenges and future developments.

\section{BIM AND BPM APPROACH: A BRIEF STATE OF THE ART}

The new methodologies and technologies, together with theories and practices usually applied to a limited phase of the process or in other fields, can be the key for cultural heritage process innovation.

\subsection{Building Information Modeling (BIM)}

The Building Information Modeling, defined as a process related to the creation and use of digital models for design, construction and operations of projects [6] has changed the paradigm of construction industry as regards not only technological aspects (software and design tools), but also the approach by users and stakeholders that are becoming more closer to the concept of standardization [7]. As the BIM model is a "shared information repository for collaboration throughout the facility's lifecycle" [8], it allows all design team members (owners, architects, engineers, contractors, suppliers, etc.) to collaborate more efficiently than using traditional processes [9]. Recently, the Building Lifecycle Management (BLM) [10] [11] is emerging as a new methodology, aiming at improving information sharing among all the phases of the building process, by providing an integrated IT environment to manage the whole building lifecycle [12].

Even if BIM/BLM has been usually adopted by the scientific community for the design and lifecycle management of buildings, some researchers have focused their studies on the value of BIM in the management and documentation of cultural heritage monuments [13]. According to Maddigan [14], the following benefits could be obtained by a 3D BIM environment:

- remote reviewing of the building;

- possibility to study the new structures in the environmental context;

- having surveys from different periods of time;

- better structures analysis thanks to images that give information about texture, massing and form;

- estimation of restorations and adaptations costs and effects before construction operations start;

- better comprehension of the building.

So, BIM methodology gives a further contribution in order to improve the sustainable valorization of the cultural heritage.

Historic Building Information Modeling (HBIM) is a solution that allows to create parametric objects from the analysis of historic data to represent architectural elements. The design of these parametric objects is based on architectural manuscripts ranging from Vitruvius to Palladio to the architectural pattern books of the 18th century. The virtual architectural elements contain information about their methods of construction and the materials used. Through a semi-automatic method, using a platform for the management of different software applications, the 3D historic building information model is realized by mapping the parametric objects onto the point cloud and image survey data [15]. "Very little work has been done in relation to modeling historic buildings and also generating BIM models from laser scan survey data" [16]. However, thanks to the diffusion of laser scanning and photogrammetry for recording cultural heritage sites and to the evolution of digital information systems, the HBIM approach is becoming a topic of great interest.

\subsection{Business Process Management (BPM) and BPMN}

The main challenge of process management in a new field, like the management of cultural heritage, is the knowledge creation. “This is widely viewed as a creative, 'black box' activity that is difficult to manage as a process but not impossible. Perhaps there are circumstances in which knowledge creation is totally unstructured, unmeasured, and unrepeatable - but in most situations, progress can still be made in this direction. One common approach to knowledge creation processes is simply to decompose them into several pieces or stages" [17].

Therefore, the Business Process Management (BPM) discipline is useful to reach the research aim, because it manages processes to improve business performance outcomes and operation agility in the manufacturing sector.

The European Association of BPM (EABPM) gives the following definition in its reference work, BPM Common 
Body of Knowledge: "Business Process Management is a systematic approach for capturing, designing, executing, documenting, measuring, monitoring, and controlling both automated and non-automated processes to meet the objectives and business strategies of a company" [18].

In addition to that, the approach creates and delivers value by linking together people, information flows, documents, changes, systems and other assets.

"Because BPM is dependent on the Internet and various Internet protocols, there have been a variety of efforts to generate software standards that would support BPM development. As part of process modelling techniques, first attempts towards standardization have emerged, and the most prominent candidate for such a process modelling standard is the Business Process Modeling Notation (BPMN)" [17].

The Business Process Model and Notation is an international and standard common language, bridging the communication gap that occurs between business process design and implementation, which has been maintained by the Object Management Group (OMG) ${ }^{1}$.

The notation allows hierarchical structuring of the process, distributing information for describing a process among several levels and several actors, from the general process flow of the highest level of the hierarchy to the process details on the lowest one [17].

The BPMN provides a detailed top-down description of a business process model, along with information flows between activities. The model is described by graphical notations in a Business Process Diagram (BPD) [19]. BPMN was developed to help businesses to understand their external and internal procedures, so that decision makers see their processes globally, and to communicate these procedures according to the specific standard [20] [21].

The application of the BPM approach for modelling in $\mathrm{BPMN}$ language the restoration process is an innovative way to map the current methodology and consequently optimizing them with BIM innovation.

\subsection{Systematic Literature Review about BIM and BPM application to the cultural heritage processes management}

To pursue the main goals of the research, namely the modeling of a cultural heritage restoration process using BPMN language and BIM methodology, a research among literature works has been carried out through a systematic literature review.

A set of keywords, related to the simultaneous application of BIM and BPM methods in the construction sector, were chosen and then used to search papers in Web of Science and Scopus bibliographic databases.

Very few papers that correlate BIM and BPM or BPMN were found and no one about the application of BPM/BPMN to HBIM processes.

Therefore, found papers refer to the application of BPMN and BIM to different topics related to the construction industry. For instance, they deal with the development of a Process Mapping Procedure for planning BIM implementation on a project [21], the development and validation of a holistic energy performance evaluation framework [22], the investigation of the requirements for BIM governance and the development of specifications for a cloud-based governance platform [23], the analysis of work process and information exchange in construction projects by focusing on the project owner [24], the definition of a Building Materials Reuse Workflow [25], the encoding of regulatory knowledge related to fire safety into a computable representation [26].

Whilst analyzed papers integrated BIM and BPM concepts for different purposes, they all agreed that mapping processes by BPMN improve the information exchange among stakeholders [24], describes business processes in detail [25] and supports transition to BIM implementation [22].

The literature review about the simultaneous application of BIM and BPM approaches to the construction sector has revealed that cultural heritage processes are not managed by BPM techniques. Furthermore, there is no integration between BIM and BPM approaches in this field.

Considering the literature review results, it would be useful to apply BPMN to HBIM process in order to point out critical points of traditional processes and to underline strengths and weaknesses of the same processes in a BIM environment. Mapping a HBIM process using BPM method results to be strategic and acquires relevance considering that very little has been done in this field.

\section{RESEARCH METHOD}

The research activities goals have been focused on the understanding of the processes through observation in the natural settings of the analyzed subject, according to qualitative research methods [27]. Data collected have been then studied in depth, in order to propose a methodology for construction sector processes analysis, which integrates knowledge from different research fields. The target of the research work has been, in particular, the restoration process of a historical building.

The present work research method includes the main qualitative characteristics reported by Creswell. More specifically, the authors have chosen a case study qualitative approach [28].

Among the multiple forms of data that a qualitative researcher can gather [29], authors have selected interviews and document analysis as sources of information. In addition to that, to ensure natural settings, data are collected at the site where participants face the issues that researchers are studying. In particular, the Italian context has been considered and engineers and architects that work in the Italian regulatory framework have been interviewed.

The researcher has a key role in data collection, management and analysis. He/she gives his/her own interpretation to data, and this often means a lack of transferability, reliability, and objectivity. To explore different perspective of the topic, authors have used investigator triangulation and data triangulation [30].

Inductive and deductive approaches have both played an important role in the data analysis [28]. Firstly, data have been organized into categories and unit of information and, secondly, HBIM principles have been included in the specific case study to be processed. 


\subsection{Research methodology}

Following the research method design, the first stage of this work has been the study of the actual historical building restoration process. Guidelines for the modeling of the analyzed process are those given by the Italian legislative framework. In detail, the Legislative Decree no. 42/2004, above mentioned, the Legislative Decree no. 380/2001 (D.P.R. Testo unico delle disposizioni legislative e regolamentari in materia edilizia) and the Legislative Decree no. 50/2016 (Codice dei Contratti Pubblici di Lavori, Forniture e Servizi) were complied with.

To correctly map the restoration process, the regulation code has been therefore studied and information has been integrated with data collected through qualitative interviews with ten subject matter experts (architects and engineers) working as freelancers on the Italian territory. These interviews have involved unstructured and open-ended questions in order to acquire knowledge from current practice.

The process has been first divided into macro-phases and for each macro-phase actors involved, their roles and responsibilities, activities and their interconnection, information exchange, resources have been identified. Particular attention has been given to documentation produced during activities, to the format used and to the sharing mode. It is in fact in this area that benefits could be significant as a BIM based system optimizes time and costs related to paper consumption, redigitation of data, redundant information and archived data for future works.

In the second stage BPMN notation has been used to represent graphically and in an international standard language the traditional cultural heritage restoration process, in its current state (As Is) BPD. The authors have translated and integrated Italian regulation codes and stakeholders' activities into BPMN, classifying process information in levels of detail, in order to give a graphic representation of the process at different informative layers.

After a critical analysis of the current process (As Is), weaknesses, bottlenecks or possible legislative code integration have been identified and studied in depth.

To improve restoration process management in the specific field of cultural heritage, HBIM requirements have been investigated and, by applying a deductive approach, changes in the traditional process have been proposed. Accordingly, the final stage of the research work has consisted in a To Be cultural heritage restoration process proposal, which integrates HBIM methodology and Business Process Management and which is illustrated in BPMN language.

\section{CASE STUDY}

The described methodology can be applied to different processes in the construction field and specifically to cultural heritage processes. To give an example of how process modeling could be a useful communication and analysis tool, authors have chosen a specific case study, hypothesizing that:

- the process analyzed is that one referred to a private property building, identified by law as a building having historical, cultural or artistic value;

- architectural, structural, plant engineering projects are managed by a design team;

- construction works are given to a building contractor, which is external to the design team.
The specific process has been then studied and mapped in BPMN language as it is in current practice, and weak points have been identified and analyzed in a critical light. The made observations have been then used to design the new restoration process (Figure 4), integrated with HBIM methodology. Both the As Is and the To Be processes have been mapped using Signavio Software and hypothesizing a starting simplification, namely that all professional figures have accepted their designation by the owner.

The BPD illustrated in Figure 4 shows the process complexity with actors involved and their interactions in the regulatory Italian framework.

The BPD is a high-level representation, which gives an idea of how many professionals and stakeholders have a role in the process, when and how they have to interact, according to the Italian law, and indicates the documentation required in a certain point of the process to a specific actor by another actor or stakeholder. However, the process is much more complex, and some activities represented in Figure 4 have been analyzed in greater depth and mapped as sub-processes, indicated in the diagram with a "+", under the graphical rules of BPMN language. In the As Is process six actors have been identified:

- the owner, assumed to be a private in this case study;

- the Superintendence, which could authorize or not the restoration of the building;

- the Local Authority, which gives the authorization for the restoration works;

- the Design Team, considered as a single actor to simplify the representation of the process, but often it has to be replaced with different professional figures (architect, structural engineer, plant engineer, etc.);

- the Contractor, in charge of the construction works;

- the Works Supervisor, who has to verify the correct execution of works.

To optimize the As Is, BIM, and more specifically HBIM principles, are evaluated and introduced in the To Be process, resulting in the introduction of new professional figures, as regards actors, namely the BIM Manager and the Facility Manager, in order to have a BIM process supervisor and a manager for use and maintenance phase management.

A "pool" has been assigned to each process actor. A pool is a rectangular box that can contain flow objects such as task and activity. Therefore, a pool is a graphical representation of the activities that participants who take part in the process have to do. Dotted lines represent communications between pools and the email message has been assumed as the main communication tool.

Another change to traditional process is the introduction of a common database, the HBIM DB (Figure 5), that contains the HBIM model, a 3D parametric and informative model and the relative documentation, which are dynamically uploaded by actors involved in specific phases. In fact, actors are allowed to manage the model in defined phases and only specific operations are available for each actor in the HBIM system. When an actor adds information to the HBIM DB, this activity is associated to a specific task and illustrated in the BPD. Thanks to the graphical representation, it becomes clear who has to enrich the HBIM DB, which piece of information he/she has to add and when, during the whole building lifecycle.

In this way information sharing is in real time and data are traceable, avoiding waste of time and optimizing costs. 


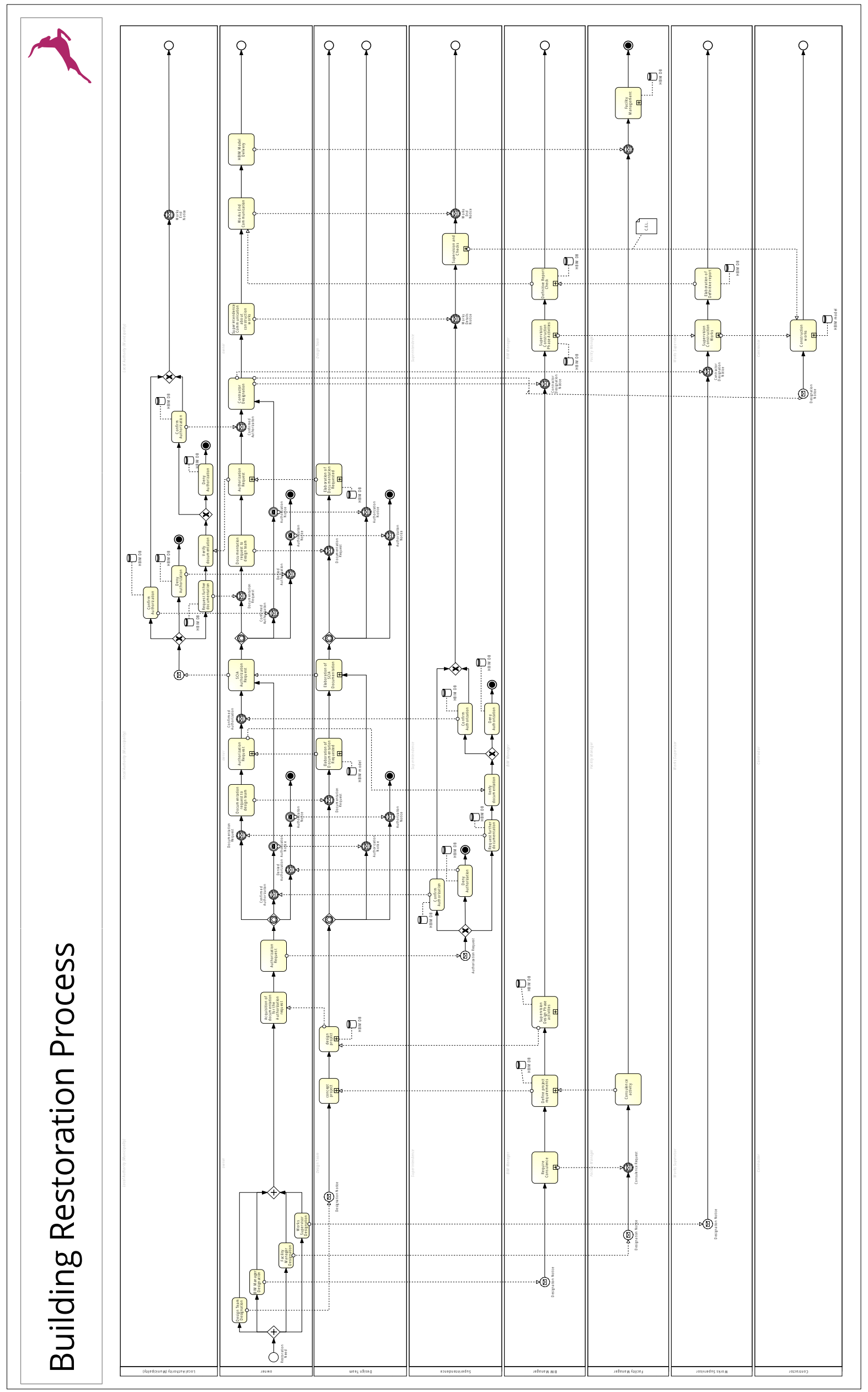

Figure 4. Historical Building Restoration Process BPD. 


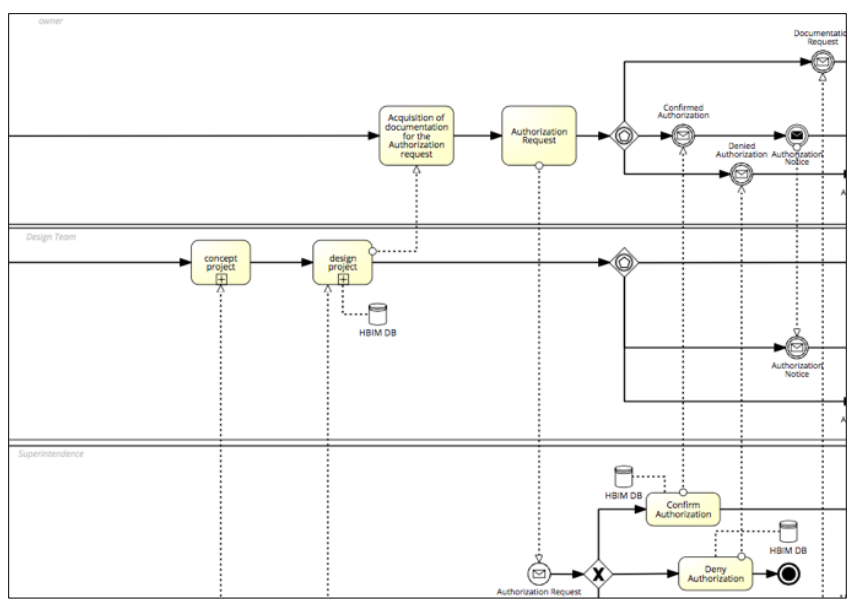

Figure 5. Process Detail: the HBIM Database for data sharing.

According to BIM logic, the BIM manager elaborates a BIM Execution Plan (BEP) to describe and establish the project requirements, that must be communicated to the design team and to managers involved at each level within the organization. To give a building lifecycle vision to the project, the Facility Manager has a role in the design phase and gives a contribution in order to define the BEP (Figure 6). The BIM manager requests advice from the Facility Manager at the beginning of the design phase and considers the point of view of a specialist that deals with the building use and maintenance phase, optimizing the project as regards for example energy efficiency or plants requirements.

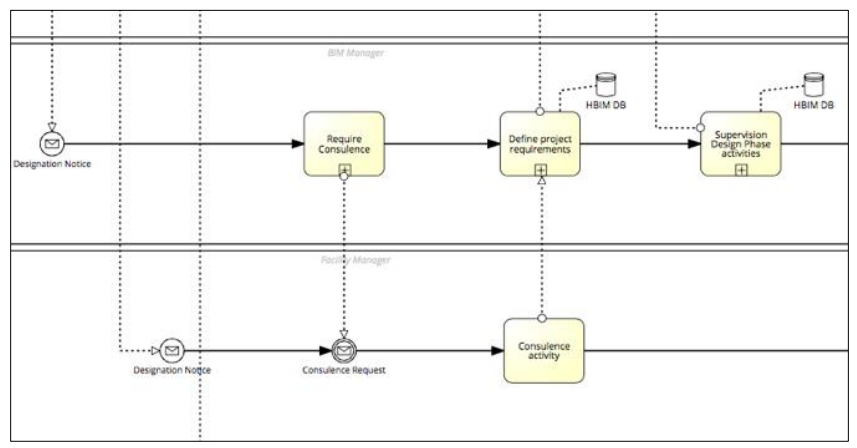

Figure 6. Definition of project requirements (BEP).

The Facility Manager is a relevant figure within the new process because a great importance has been given to building preservation, conservation and maintenance. The Facility Management has been, in fact, enabled through the HBIM model, delivered by the owner to the facility manager (Figure 7). The HBIM model is the container of all the information associated to the building. These data are useful to better plan the building management and to design all the possible changes during its lifecycle.

For a historical building, it is essential to preserve its original characteristic in order to keep its artistic and historical value. Storing data about materials, structure, but also previous restoration activities in a common database is a key factor for HBIM methodology application.

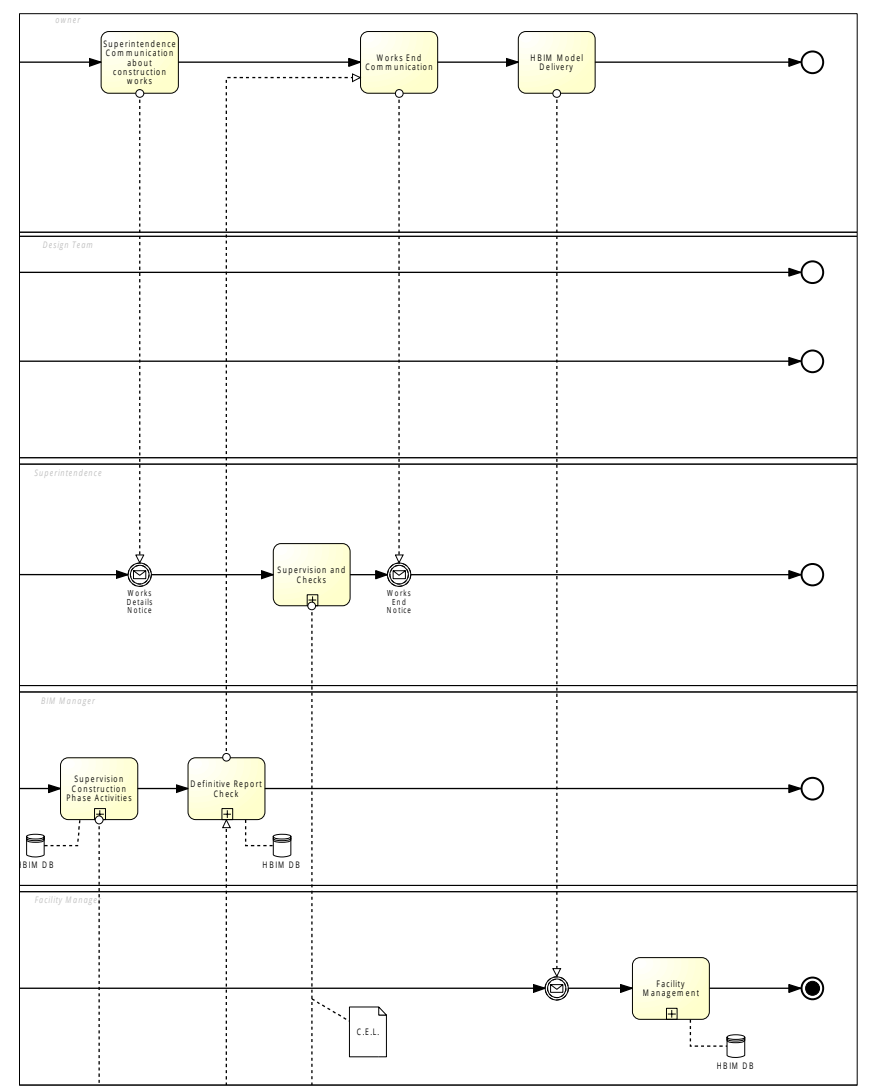

Figure 7. Facility Management Phase.

\section{DISCUSSIONS}

The application of the methodology to the cultural heritage restoration process has led the authors to underline the benefits of an integrated management approach.

Firstly, the digital model allows knowledge sharing among all the stakeholders involved in the whole building lifecycle and facilitates document exchange during the lifecycle of the building.

Secondly, this methodology allows to integrate into one single process different laws that are not connected to each other, although all these laws are referred to restoration processes. In fact, a critical point of this study has been to find correspondence among laws, as regards above all the interactions between actors and documentation.

In addition to that, the use of an open standard graphical approach, such as BPMN, facilitates communication and makes easier the full comprehension of processes by stakeholders. Nevertheless, BPMN language is not considered suitable for the detailed description of documental exchange in this case.

The methodology proposed is also replicable, since it could be applied to other similar processes in the construction industry, as new construction, urban renovation, etc.

Furthermore, the link with HBIM environment simplifies the documentation, archived in the HBIM Database, and operations management related to the historical building, by enabling ordinary and extraordinary dynamic maintenance. This aspect is an important objective for the management of the building historical heritage. Thanks to the HBIM DB, in fact, the facility manager has a picture of the state of the building and can plan maintenance or restoration works giving priority to the interventions which are more necessary, if economic resources are limited. A programmed maintenance is also a way 
to prevent serious damage that requires more expensive operations.

Particular attention has been given to the management of use and maintenance phases in order to cover all the dimensions related to the building, giving to the construction industry sector methodologies and tools to innovate processes and increase construction processes sustainability.

However, there are some critical points in HBIM models, that have to be overcome, in order to reach better results in the application of the proposed methodology. For instance, the lack of standardization and the difficulty in the management of a huge quantity of surveys, geospatial and administrative data have been considered crucial aspects. Solutions to these issues could be: a) enrich HBIM models with the Web Ontology Language (OWL) standards; b) use open libraries, that could be customized according to local materials and constructive techniques [31].

\section{CONCLUSION AND FUTURE RESEARCH}

After an analysis of current cultural heritage restoration process, this research describes a methodology proposal for the optimization of the historical buildings restoration As Is process, consisting in the mapping of the To Be process using BPM technique and HBIM approach. This methodology has been proposed with the aim of innovating cultural heritage management.

The main goal has been the reengineering of current procedures and activities, characterized by several actors, many procedures, long work periods and fragile assets to be maintained.

BPM approach has allowed to study in depth the process related to the restoration of a historical building, by fostering activities standardization and facilitating the identification of stakeholders, documents, procedures and bottlenecks that would be otherwise hardly identified. This analysis has included the reengineering of the process thanks to the integration of the BIM methodology, focused on the creation and management processes of a digital model. The challenge of a BIM-based approach is the centralized Database. The HBIM DB is proposed as a strategy to manage the as-built heritage and to store the main information and documents regarding the historical buildings.

The proposed methodology BIM and BPM based could be useful for the public authorities, responsible for the cultural heritage management, and for the owners for planning the maintenance of the historical buildings in a structured and dynamic common data environment.

The next steps will focus on the process improvement, the analysis of other processes related to cultural heritage and on the automatization of some HBIM functionalities for document exchange among different stakeholders.

\section{ACKNOWLEDGEMENT}

This paper is based on a greater research started inside the Core Lab, a research laboratory of the Department of Innovation Engineering, University of Salento. To this aim, authors would thank colleagues Antonio Margarito, Computer Engineer, and Marco Esposito, Management Engineer, who provided insight and expertise on BPMN that greatly assisted the presented work.
Authors gratefully acknowledge the support received from the Italian Ministry of University and Research, through the PRIN 2015 funding scheme (project 2015JW9NJT - Advanced mechanical modeling of new materials and structures for the solution of 2020 Horizon challenges).

\section{REFERENCES}

[1] A. Malagnino, G. Mangialardi, A. Corallo, G. Zavarise, Business Process Management and Building Information Modeling for the innovation of cultural heritage renovation process, Proc.of the $3^{\text {rd }}$ IMEKO International Conference on Metrology for Archaeology and Cultural Heritage, pp. 184-189, 23-25 October 2017.

[2] I. C. T. C. ICOMOS, ICOMOS, International Cultural Tourism Charter, 2002.

[3] [Online]. Available: http://www.casa24.ilsole24ore.com/art/condominio/2012-1010/limmobile-storico-sempre-vincolato172250.php?uuid=AbGt4RrG.

[4] S. Boschert, R. Rosen, Digital Twin-The Simulation Aspect, in Mechatronic Futures, Springer, Cham, 2016.

[5] C. Brandi, Teoria del restauro, Ed. di storia e letteratura ed., 1963.

[6] J. Underwood, U. Isikdag, Handbook of Research on Building Information Modeling and Construction Informatics: Concepts and Technologies, Hershey: IGI Publishing, 2009, pp. 65-103.

[7] T. Dalla Mora, F. Peron, F. Cappelletti, P. Romagnoni, P. Ruggeri, Una Panoramica sul Building Information Modeling (BIM), Cultura e Tecnica per Energia Uomo e Ambiente, 2014.

[8] P. Suermann, R. Issa, Evaluating Industry Perceptions of Building Information modeling (BIM) impact on construction, ITcon, Journal of Information and construction, vol. 14, pp. 574 594, 2009.

[9] J. Carmona, K. Irwin, BIM: Who, what, how and why, 2007. [Online]. Available: http://www.facilitiesnet.com/software/article/BIM-Who-WhatHow-and-Why--7546.

[10] T. Froese, Future directions for IFC-based interoperability, Vols. 8, Special Issue IFC - Product models for the AEC arena, ITcon, 2003, pp. 231-246.

[11] D. Migilinskasa, V. Popov, V. Juoceviciusc, L. Ustinovichiusd, The Benefits, Obstacles and Problems of Practical Bim Implementation, vol. 57 Procedia Engineering, Elsevier, 2013, pp. 767-774.

[12] L. Ustinovičusa, R. Rasiulis, L. Nazarkoc, T. Vilutieneb, M. Reizgeviciusb, Innovative research projects in the field of Building Lifecycle Management, Procedia Engineering, no. 122, pp. 161-171, 2015.

[13] S. Fai, K. Graham, T. Duckworth, N. Wood, R. Attar, Building Information Modeling and Heritage Documentation, in CIPA 2011 Conference Proc. of the XXIIIrd International CIPA Symposium, 2011.

[14] J. Maddigan, HCF National Heritage Summit, Canadian Association of Heritage Professionals, 2012.

[15] M. Murphy, E. McGovern, S. Pavia, Historic Building Information Modelling - Adding intelligence to laser and image based surveys of European classical architecture, ISPRS Journal of Photogrammetry and Remote Sensing, vol. 76, p. 89-102, 2013.

[16] C. Dore, M. Murphy, Integration of Historic Building Information Modeling and 3D GIS for Recording and Managing Cultural Heritage Sites, in $18^{\text {th }}$ International Conference on Virtual Systems and Multimedia: Virtual Systems in the Information Society, Milan, 2012.

[17] J. Vom Brocke, M. Rosemann, Handbook on business process management, Heidelberg: Springer, 2010.

[18] J. Freud, B. Rucker, Real-Life BPMN (3rd edition): With introductions to CMMN and DMN, Camunda, 2016. 
[19] M. A. Lopez-Campos, A. Crespo Marquez, J. F. Gomez Fernandez, Modelling using UML and BPMN the integration of open reliability, maintenance and condition monitoring management systems: An application in an electric transformer system, Computers in Industry, vol. 64, no. 5, pp. 524-542, 2013.

[20] R. Flowers, C. Edeki, Business Process Modeling Notation, Journal of Computer Science and Information Technology, vol. 2, no. 3, pp. 35-40, 2013.

[21] C. Saluja, A process mapping procedure for planning building information modeling (BIM) execution on a building construction project., 2009.

[22] M. Eguaras-Martínez, C. Martín-Gómez, M. Vidaurre-Arbizu, T. Brennan, S. Krinidis, D. Ioannidis, D. Tzovaras, Architectural Simulation of the Integration of Building Information Modelling (BIM) \& Business Process Modelling (BPM), 2014.

[23] E. Alreshidi, M. Mourshed, Y. Rezgui, Cloud-based BIM governance platform requirements and specifications: software engineering approach using BPMN and UML, Journal of Computing in Civil Engineering, 2015.

[24] V. Likhitruangsilp, P. Ioannou, S. Leeladejkul, Mapping Work Process and Information Exchange of Construction Entities for BIM Implementation: Case Study of an Academic Institute, Computing in Building and Civil Engineering, 2014.

[25] A. K. Ali, R. Badinelli, Novel Integration of Sustainable and Construction Decisions into the Design Bid Build Project
Delivery Method Using BPMN, in International Conference on Sustainable Design, Engineering and Construction, 2016.

[26] J. Dimyadi, C. Clifton, M. Spearpoint, R. Amor, Regulatory Knowledge Encoding Guidelines for Automated Compliance Audit of Building Engineering Design, in International Conference on Computing in Civil and Building Engineering, 2014.

[27] Z. Irani, J. Ezingeard, R. Grieve, P. Race, A case study strategy as part of an information systems research methodology: a critique, International Journal of Computer Applications in Technology, vol. 12, no. 1999, pp. 190-198.

[28] J. Creswell, J. Creswell, Research Design: Qualitative, Quantitative, and Mixed Methods Approaches, Los Angeles: SAGE Publications, 2018.

[29] C. Marshall, G. Rossman, Designing qualitative research, Thousand Oaks, CA: SAGE Publications, 1999.

[30] Z. Zhou, Qualitative research in Engineering Management, Virginia Beach, Virginia, USA: American Society for Engineering Management, 2012.

[31] C. Di Biccari, A. Malagnino, A. Corallo, G. Zavarise, Building Information Modeling or Cultural Heritage: Beyond Asset Modeling. A pragmatic comparison of literature case studies, in Proc. of the $3^{\text {rd }}$ IMEKO International Conference on Metrology for Archaeology and Cultural Heritage. MetroArchaeo 2017, Lecce, 2017. 